Published in final edited form as:

Adv Surg. 2011 ; 45: 197-209.

\title{
Advances in the Surgical Management of Gastrointestinal Stromal Tumor (GIST)
}

\author{
Umer I. Chaudhry, MD ${ }^{1}$ and Ronald P. DeMatteo, MD ${ }^{2,{ }^{*}}$ \\ ${ }^{1}$ Department of Surgery, Naval Hospital Camp Pendleton, Camp Pendleton, CA \\ ${ }^{2}$ Hepatopancreatobiliary Service, Memorial Sloan-Kettering Cancer Center, New York, NY
}

\section{Abstract}

Gastrointestinal stromal tumor (GIST) is an uncommon sarcoma of the intestinal tract. In the past decade, GIST has received considerable attention, as it serves as a model for the molecular therapy of solid tumors. While surgical resection remains the mainstay of curative treatment of the primary localized GIST, small molecule tyrosine kinase inhibitors have radically changed therapy of locally advanced and metastatic disease. Multimodal treatment integrating surgery and oncoprotein-targeted therapy has shown significant promise. In this article, we will summarize the advances in the multidisciplinary management of primary and recurrent GIST.

\section{Keywords}

gastrointestinal stromal tumor; GIST; KIT; surgery

\section{BACKGROUND}

GIST is a mesenchymal tumor that typically arises from the alimentary tract. ${ }^{1}$ In the past, these tumors were classified as leiomyomas, leiomyosarcomas or leiomyoblastomas.Only recently has it become evident that GIST is a separate entity and the most common sarcoma of the gastrointestinal (GI) tract,with an annual incidence in the United States of approximately $5,000 .^{2}$

GIST is believed to arise from the KIT(CD117) proto-oncogene positive interstitial cell of Cajal, ${ }^{3}$ the pacemaker cell of the GI tract. Approximately $85 \%$ of GISTs harbor an activating KIT mutation, which leads to constitutive activation of KIT and its tyrosine kinase function. ${ }^{4}$ KIT is involved in many cellular functions, including cell differentiation, growth, and survival. Binding of KIT to its ligand leads to dimerization and subsequent autophosphorlyation of KIT, which initiates a cascade of intracellular signaling leading to adhesion, differentiation, proliferation, and tumorigenesis. About 3-5\% of GISTs instead carry a mutation in the platelet derived growth factor receptor a (PDGFRa) gene. ${ }^{5}$ Interestingly, 10-15\% of the tumors contain the wild-type forms of the KIT and PDGFRa proto-oncogenes, yet still overexpress KIT. ${ }^{6}$

In 2001, Joensuu et al. published their experience with imatinib mesylate (Gleevec; Novartis Pharmaceuticals, Basel, Switzerland), a small-molecule tyrosine-kinase inhibitor, to treat

\footnotetext{
*Corresponding Author: Ronald P. DeMatteo, MD, Memorial Sloan-Kettering Cancer Center, Box 203, 1275 York Avenue, New York, NY 10065, Tel: (212) 639-5876, Fax: (212) 639-4031, dematter@mskcc.org. DISCLOSURES

Ronald P. DeMatteo has served on advisory boards for Novartis and received honoraria.
} 
metastatic GIST in a single patient. ${ }^{7}$ Dramatic regression of the disease was evident on serial imaging, and thus began the paradigm shift in the treatment of GIST. At present, with approximately an $80 \%$ response rate to imatinib, compared with a dismal $5 \%$ response to conventional cytotoxic agents, the median survival in patients with metastatic GIST has increased to 5 years from 15 months in the era prior to tyrosine kinase inhibitors. ${ }^{8}$

Molecular targeted therapy has truly revolutionized the treatment of patients with metastatic GIST and provided an opportunity for adjuvant and primary systemic therapy for localized and recurrent disease.

\section{CLINICAL PRESENTATION}

GISTs demonstrate a fairly equal distribution between men and women, however some literature suggest that there is a slight male predominance. ${ }^{9}$ Although GIST has been reported in patients of all ages, including children, most of the people affected by the disease are between $40-80$ years old at the time of diagnosis, with a median age of 60 years. The majority of GISTs are sporadic. Nonetheless, there are several case reports of familial germline mutations in the KIT or PDGFRa proto-oncogenes. ${ }^{10,11}$

Approximately $60 \%$ of GISTs occur in the stomach, while $30 \%$ of cases are found in the small intestine, $5 \%$ in the rectum, and 5\% in the esophagus (Figure 1). ${ }^{9}$ Rarely, they can also develop in the omentum, mesentery, pancreas, or other retroperitoneal organs. ${ }^{12}$

The majority (70\%) of the patients diagnosed with GIST has vague symptoms, such as abdominal pain, GI bleeding from a mucosal erosion, or an abdominal mass. ${ }^{13}$ Ten percent of the cases are detected only at the time of autopsy. Intestinal obstruction from GISTs is rare, since GISTs behave like other sarcomas and usually displace rather than invade adjacent structures. Occasionally, however, they may serve as lead points for intussusception. Patients with esophageal or duodenal GIST may rarely present with dysphagia or jaundice, respectively.

\section{DIAGNOSIS AND EVALUATION}

Due to the infrequency of GIST, the disease is rarely suspected prior to the time of surgery. A high index of suspicion is required to make the diagnosis. The best radiological study to characterize a mass suspicious for GIST, as well as to evaluate the extent of the disease, is a contrast-enhanced computed tomography (CT) of the abdomen and pelvis. Metastases to the lungs or other extra-abdominal locations are usually observed only in advanced cases. On a CT scan, GISTs typically appear as hyperdense, enhancing masses, closely associated with the stomach or small intestine (Figure 2). The liver and peritoneal surface are the most common sites of metastatic disease. Lymph node metastases are rare, except in the pediatric population. ${ }^{14}$ Children are also more likely to present with multifocal disease and lack a KIT or PDGFRa mutation.GISTs may appear heterogeneous due to central necrosis or intratumoral hemorrhage. Magnetic resonance imaging (MRI) may be useful in rectal GIST. Positron emission tomography (PET) is not specific enough for the diagnosis of GIST, but can be used to monitor the clinical response to imatinib treatment, although it is rarely needed. On endoscopy, GIST appears as a submucosal mass, since it originates from the bowel wall and not the mucosa. This can be confirmed via endoscopic ultrasound. Often, however, endoscopic evaluation is noncontributory.

Recent studies have shown that endoscopic fine needle aspiration (FNA) for the diagnosis of GIST has a sensitivity as high as $80 \% .{ }^{15}$ However, preoperative tissue diagnosis is usually not necessary unless the diagnosis is in doubt. A biopsy is recommended for metastatic disease or if neoadjuvant imatinib is under consideration. 


\section{PROGNOTIC FACTORS}

In GIST, a gain-of-function mutation in $K I T(85 \%)$ leads to constitutive activation of KIT and its tyrosine kinase function. Several mutations have been described, the most common being KIT exon 11 (70\%) and exon $9(10 \%) .{ }^{4}, 6$ As mentioned previously, 3-5\% of GISTs harbor a mutation in the PDGFRa proto-oncogene, while 10-15\% of tumors carry wild-type alleles of KIT and PDGFRa, yet overexpress KIT. GISTs may also be positive for CD34 (60-70\%), smooth-muscle actin (SMA; 30-40\%), S-100 protein (5\%), and rarely desmin. ${ }^{16}$ Unlike other GI malignancies, the behavior of GIST is difficult to predict based on histopathology alone. Although the best indicator of malignancy is the confirmation of metastatic disease, three characteristics have been shown to predict how GISTs will behave size, mitotic rate, and tumor location. ${ }^{17}$ In general, GISTs of $10 \mathrm{~cm}$ or greater in size are more likely to recur. Mitotic index is the dominant predictor of recurrence, as tumors with at least 5 mitoses per 50 high powered fields (HPF) are 15 times more likely to recur than those with less than 5 mitoses per $50 \mathrm{HPF}$. Also, GISTs originating in the small intestine exhibit a more aggressive behavior than those of similar size and mitotic index originating in the stomach. Importantly, neither small size nor low mitotic rate excludes the potential for malignant behavior. Patients with either a KIT exon 9 mutation or KIT exon 11 deletion involving amino acid W557 and/or K558 experience a higher rate of recurrence, while point mutations and insertions of KIT exon 11 confer a more favorable prognosis.

Recently, Gold and colleagues developed a GIST prognostic nomogram based on tumor size $(\mathrm{cm})$, location of disease (stomach, small intestine, colon, rectum, or other) and mitotic index ( $<5$ or $\geq 5$ mitoses per $50 \mathrm{HPF}$ ) from 127 patients treated at Memorial Sloan-Kettering Cancer Center (MSKCC) between 1983 and 2002. ${ }^{18}$ It predicts recurrence free survival at 2 and 5 years after complete surgical resection of localized primary GIST (Figure 3 ). The authors validated the nomogram using a series of patients from the Mayo Clinic and another series from the Spanish National Registry, and showed better predictive accuracy than those of two commonly used staging systems developed at the NIH GIST workshop and the AFIPMiettinen staging system. ${ }^{19}$ Including the presence or type of KIT or PDGFRa mutation did not improve the discriminatory ability, although this may be due to limited sample sizes.

\section{TREATMENT}

Successful treatment of GIST requires assessment of the extent and progression of disease, and integration of surgery and molecular-targeted therapy. Thus, a multidisciplinary team that includes radiologists, medical oncologists, pathologists, and surgeons is paramount for the effective care of these patients.

\section{Primary GIST}

For patients with primary localized GIST, surgical extirpation remains the only chance for cure. The goal of the operation is to achieve a negative microscopic margin (R0 resection) with an intact tumor pseudocapsule. At exploration, careful examination of the liver and peritoneal surfaces for previously undetectable metastatic disease should be performed. Care should be exercised to avoid excessive tumor manipulation, which can disrupt what may be a friable tumor and lead to bleeding and intraperitoneal dissemination. Resection can usually be accomplished with only a wedge resection of the stomach or a segmental resection of the small bowel. In a series of 140 patients with gastric GISTs, 68\% underwent a wedge resection, $28 \%$ required a partial gastrectomy, and only $4 \%$ needed a total gastrectomy. ${ }^{20}$

Extensive surgery is occasionally required for larger or poorly positioned tumors, such as those near the gastroesophageal junction, periampullary region, or distal rectum. Since GIST does not typically exhibit an intramural spreading behavior, wide margins of resection are 
not necessary and have not been associated with better prognosis, although every effort should be spent to obtain gross negative margins. ${ }^{9}$ Re-excision of disease in patients who underwent an inadvertent $\mathrm{R} 1$ resection should be considered on a case-by-case basis, due to the lack of evidence supporting a clear association between microscopically positive margins and poorer survival outcomes. Laparoscopic resection of primary GIST may be considered by surgeons experienced in this approach. Standard oncologic principles still apply. A laparoscopic R1 resection should not be accepted if laparotomy guarantees an R0 resection. GISTs measuring $1.0-8.5 \mathrm{~cm}$ in size have been successfully treated with minimally invasive techniques. ${ }^{21}$ Since GISTs rarely metastasize to lymph nodes, formal lymphadenectomy is not necessary unless locoregional lymph nodes are enlarged. When adherence to adjacent organs is identified, an en bloc resection is favored.

Complete gross resection is possible in $85 \%$ of patients with primary, localized GISTs. Nevertheless, without any further treatment, at least $50 \%$ of patients develop tumor recurrence and 5-year survival rate is approximately 50\%. ${ }^{9,2}$ Postoperative adjuvant chemotherapy for the treatment of GIST has generally not been recommended due to dismal response rates of traditional chemotherapeutic agents. ${ }^{23}$ Radiotherapy is also of limited value, due to the location of the tumors and the limit this places on the doses that can be safely employed. Radiation, however, may be useful for some pelvic GISTs. Treatments such as hepatic artery embolization and debulking surgery followed by intraperitoneal chemotherapy have also been investigated but with relatively discouraging results. ${ }^{24,25}$

The application of imatinib mesylate in the treatment of GIST reflects a major advance in the therapy of solid tumors with specific molecular targeting and has become the first-line medical treatment for metastatic, unresectable, or recurrent GIST. ${ }^{26}$ The landmark case report of Joensuu and colleagues prompted Phase II and III clinical trials to confirm the efficacy of imatinib in the treatment of metastatic or unresectable GIST. In 2002, Demetri et al. published results of a Phase II trial establishing that $400 \mathrm{mg} / \mathrm{day}$ or $600 \mathrm{mg} / \mathrm{day}$ of imatinib can lead to sustained objective response in patients with metastatic or advanced unresectable GIST. ${ }^{27}$ The initial median follow-up was 6 months and over $80 \%$ of patients showed either disease regression or stabilization. A subsequent long-term analysis demonstrated a median survival of 57 months, as compared to 15-20 months for historical controls. ${ }^{8}$ A Phase III trial published in 2008 confirmed the effectiveness of imatinib as primary systemic treatment for patients with unresectable or metastatic GIST. ${ }^{28,} 29$

Adjuvant Imatinib-Since 50\% of patients with complete resection of their primary localized GIST develop recurrent disease, and given the paucity of effective chemotherapeutic agents, the use of adjuvant imatinib after complete resection of primary GIST was evaluated in a Phase II trail lead by American College of Surgeons Oncology Group (ACOSOG; ACOSOG Z9000). ${ }^{30}$ The study analyzed the effects of adjuvant imatinib at a dose of $400 \mathrm{mg} /$ day for 1 year after complete resection of primary GIST in 107 high-risk patients. High risk was de ned as a tumor size $>10 \mathrm{~cm}$, intraperitoneal tumor rupture or hemorrhage, or multifocal (<5) tumors. At a median follow-up of 4 years, the 1, 2, and 3 year overall survival rates were 99,97 , and $97 \%$, respectively, while the recurrence-free survival rates were 94,73 , and $61 \%$, respectively. Data from this trial established that imatinib is well tolerated in the adjuvant setting, prolongs recurrence-free survival, and is associated with improved overall survival when compared with historical controls.

In 2009, a Phase III ACOSOG intergroup trial was published (Z9001). ${ }^{31}$ Patients were randomized to imatinib $400 \mathrm{mg} /$ day $(\mathrm{n}=359)$ or placebo $(\mathrm{n}=354)$ for 1 year after undergoing complete resection of their localized, primary GIST ( $\geq 3 \mathrm{~cm}$ tumor size). Accrual to the trial was halted based on the results of a planned interim analysis of 644 evaluable patients. At median follow-up time of 19.7 months, 30 (8\%) patients in the imatinib group and $70(20 \%)$ 
patients in the placebo arm had developed recurrent disease or had died. Patients assigned to the imatinib arm had a 1 year recurrence-free survival of $98 \%$, compared to $83 \%$ in the placebo arm. No difference in overall survival between the two treatment arms was noted. However, longer follow-up of the cohort will establish the impact of adjuvant imatinib on overall survival.

On the bases of the Phase III ACOSOG intergroup trial, the FDA and European Medicines Agency (EMEA) approved the use of adjuvant imatinib in 2008 and 2009, respectively. However, due to the high financial cost of treatment and the potential side effects of imatinib, the ability to measure the risk of recurrence for an individual patient is desirable. We expect that the prognostic nomogram developed by Gold et al. can be used to help identify which patients benefit from adjuvant therapy. ${ }_{18}$

Neoadjuvant Imatinib—Neoadjuvant imatinib is particularly attractive for patients with large or poorly localized primary tumors that would otherwise require extensive surgery or sacrifice of a large amount of normal tissue. Neoadjuvant therapy with the intent of cytoreduction may convert the surgical treatment of a rectal GIST from an abdominoperineal resection to a low anterior resection. Early results of a nonrandomized Phase II trial testing neoadjuvant/adjuvant imatinib mesylate for primary advanced and potentially operable metastatic/recurrent GIST, led by the Radiation Therapy Oncology Group (RTOG), were recently published. ${ }^{32}$ Sixty-three patients entered the trial, 52 were analyzed with 30 patients having primary advanced GIST (Group A; size $25 \mathrm{~cm}$ ) and 22 patients with metastatic/recurrent disease (Group B; size $\geq 2 \mathrm{~cm}$ ). Results showed that preoperative imatinib $(600 \mathrm{mg} /$ day x $8-12$ weeks) followed by postoperative imatinib (600 $\mathrm{mg}$ /day x 24 months) for patients with advanced primary or potentially operable metastatic/ recurrent GIST is well tolerated, with minimal toxicity and post-surgical complications. Response (as measured by RECIST) in Group A was 7\% partial, $83 \%$ stable, and $10 \%$ unknown, and in Group B 4.5\% partial, 91\% stable, and 4.5\% progression. The two-year progression free survival was $83 \%$ in Group A and 77\% in Group B, with an estimated overall survival of $93 \%$ in Group A and $91 \%$ in Group B.

At the time of this writing, no phase III trials assessing the neoadjuvant use of imatinib have been published, although the above mentioned phase II data illustrate that the use of imatinib in a preoperative setting is feasible and not associated with notable postoperative complications. A phase III trial to study the role of neoadjuvant imatinib is certainly warranted, but accrual may be problematic.

As there is now effective treatment for recurrent or metastatic GIST, the 2009 National Comprehensive Cancer Network (NCCN) guidelines recommend CT scans of the abdomen and pelvis with IV contrast every 3-6 months during the first 3-5 postoperative years and perhaps yearly thereafter. ${ }^{2}$

\section{Recurrent GIST}

The majority of patients undergoing complete resection of their primary GIST will develop tumor recurrence. ${ }^{9}$ The median time to recurrence is reported to range from 18-24 months. At the time of recurrence, approximately two-thirds of the patients have liver involvement and half present with peritoneal disease. Extra-abdominal metastasis to lung or bone may develop as the disease progresses. Surgery alone has limited efficacy in recurrent or metastatic GIST. Excision of peritoneal disease is usually followed by subsequent recurrence. Although liver metastases are usually multifocal, approximately $26 \%$ of the patients are still candidates for resection. ${ }^{33}$ However, essentially all of the patients develop recurrent disease after hepatic resection. 
In patients for whom curative surgery is not feasible, or who develop recurrent metastatic disease, imatinib is now the first line treatment, with few exceptions. Patients who have primary GIST with synchronous, low volume metastatic disease may be considered for surgical resection rst, especially if they are symptomatic from the primary tumor.

In patients with metastatic or recurrent GIST, imatinib is reported to produce a partial tumor response in $50 \%$ of patients and stable disease in approximately $30 \%$. Remarkably, the 2year survival of patients with metastatic disease is now reported to be approximately $70 \%$, and median survival has improved to nearly 5 years. ${ }^{27,28,34}$ By contrast, before the introduction of imatinib, the median survival after surgical resection of recurrent GIST was only 15 months.

Current recommendations for a patient with locally advanced or recurrent metastatic disease are to start imatinib at $400 \mathrm{mg}$ daily. ${ }^{2}$ When unequivocal progression is observed, the dose can be increased incrementally up to $800 \mathrm{mg}$ daily, as permitted by toxicity. However, the success of this strategy appears to be limited, except in tumors with primary mutations in KIT exon 9 (10\% of GISTs). Since imatinib rarely induces a complete response and the median time to progression with imatinib therapy is less than 24 months, a multimodal approach utilizing surgical resection in conjunction with imatinib therapy to treat recurrent metastatic GIST is highly desirable. In a recent study from MSKCC, ${ }^{35} 40$ patients with metastatic GIST were treated with imatinib for a median of 15 months prior to surgical resection. Based on preoperative serial radiologic imaging, patients who had stable or responsive disease on imatinib had a 2-year progression free survival of $61 \%$ and 2-year overall survival of $100 \%$ after surgical resection. In contrast, patients who experienced focal resistance of their disease progressed at a median of 12 months postoperatively, with a 2year overall survival of just $36 \%$. Patients with multifocal resistant disease progressed postoperatively at a median of 3 months and experienced a 1-year overall survival of $36 \%$. Based on these results, selected patients with metastatic GIST who have responsive disease or focal resistance to imatinib may bene $t$ from resection. However, surgery is generally not recommended in patients with metastatic GIST and multifocal resistance. Similar results were observed by Gronchi et al. in a study employing 38 patients with advanced GIST who underwent surgery following a variable period of imatinib therapy. ${ }^{36}$ Additionally, Raut et al. published their series of 69 patients with advanced GIST who underwent surgery and concluded that patients with advanced GIST exhibiting stable disease or minimal progression on kinase inhibitor therapy have prolonged overall survival after debulking procedures. ${ }^{37}$ Surgery is usually futile in patients with generalized progression of disease while on therapy, unless to provide symptomatic relief.

Our experience suggests that the risk of disease progression on imatinib therapy, and hence developing imatinib resistance is proportional to the amount of residual viable GIST. Therefore, once maximal response to imatinib occurs (generally after 2-6 months of therapy), we evaluate patients with metastatic disease for complete resection. Imatinib therapy is continued postoperatively, unless precluded by toxicity, to delay or prevent subsequent disease recurrence, although the optimal duration of therapy is unknown. ${ }^{38}$ The risk of interrupting imatinib therapy was clearly demonstrated in a recent study by the French Sarcoma Group. Eighty-one percent of patients with responsive or stable disease while on imatinib therapy experienced rapid disease progression when imatinib was stopped. ${ }^{39}$

The success of imatinib in treating patients with GIST is de ned by lack of disease progression, rather than shrinkage of existing tumors. ${ }^{40}$ When metabolic and anatomic imaging is combined, GISTs that respond to molecular therapy may be stable in size but demonstrate areas of necrosis. When using these criteria, $12 \%$ of patients with GIST who 
are treated with imatinib demonstrate primary resistance, defined as progression within the first 6 months of imatinib treatment. Clinical studies have demonstrated that the location of mutations in the pathogenic kinase is an important factor in both treatment response and development of resistance to imatinib. Patients who experience primary resistance usually express both wild-type $K I T$ and $P D G F R a$, or contain mutations in exon 9 of KIT or a D842V mutation in PDGFRa.$^{41,42}$ Secondary or late resistance therefore occurs in patients who have initially demonstrated stabilization of their disease for at least 6 months.

Unfortunately, most patients who initially demonstrate a clinical response to imatinib will subsequently develop (secondary) resistance, as a result of additional point mutations in the KIT kinase domains. ${ }^{43,44}$ Usually, most resistant GISTs with a secondary mutation have a primary mutation in exon 11 . The second site mutations are mainly substitutions involving exons 13, 14, and 17 of KIT, corresponding to the kinase domain. Recent studies suggest that patients with primary KIT mutations in exon $13 \mathrm{~K} 642 \mathrm{E}$ and in exon $14 \mathrm{~T} 670 \mathrm{I}$ have acquired resistance to imatinib. ${ }^{41,42}$

There is general agreement that multifocal resistance to imatinib should be treated with another targeted agent such as sunitinib (P zer, New York, NY), 2,45 which has activity against KIT and PDGFRa, as well as the vascular endothelial cell growth factor receptor (VEGFR), fms-like tyrosine kinase 3 (Flt3) receptor, and the RET receptor. Sunitinib may also have activity in GISTs harboring secondary KIT mutations. ${ }^{45}$ In 2007, Demetri et al. published their experience with sunitinib in 207 patients with advanced GIST who were resistant to or intolerant of previous treatment with imatinib. The median time to tumor progression was 27.3 weeks on sunitinib and 6.4 weeks on placebo. ${ }^{46} \mathrm{In}$ a recent study by Raut and colleagues, ${ }^{47}$ impact of surgery in 50 imatinib-resistant patients on second-line sunitinib therapy was evaluated. In contrast to imatinib-responsive patients undergoing cytoreductive surgery, response to sunitinib did not correlate with a better survival outcome. Incomplete resections were frequent (50\%) and complication rates were high (54\%), although not surprising, given the advanced nature of the disease and extensive surgical history of the cohort. The ideal candidate for surgery on sunitinib, thus, remains undefined.

Further understanding of the mechanisms of resistance to imatinib may allow for the delay or prevention of this phenomenon. Additionally, a number of other agents, which interact with alternate moieties on the KIT protein, are currently in clinical trials and thus resistance to one drug may not preclude a therapeutic bene $t$ from another. ${ }^{2}$ A proposed algorithm for treatment of primary and recurrent metastatic GIST is outlined (Figure 4).

\section{SUMMARY}

Imatinib mesylate has revolutionized the treatment of GIST. Dramatic changes in clinical practice have been observed in the last decade. Nonetheless, time has also revealed the limitations of treating GIST with a single agent alone, as resistance to imatinib has become a significant clinical dilemma. Surgical resection still remains the only chance for a cure. However, it is clear that GIST is a complex disease and requires effective integration of surgery and targeted therapy to reduce recurrence after resection of primary GIST or to prolong survival in metastatic disease. Recent studies have begun to delineate the feasibility of multimodal treatment of this disease. Knowledge gained thus far, along with ongoing and future investigations of GIST, will be extremely relevant to the potential use of molecular targeted therapy for other solid neoplasms.

\section{Acknowledgments}

None. 


\section{References}

1. Mazur MT, Clark HB. Gastric stromal tumors. Reappraisal of histogenesis. Am J Surg Pathol. Sep; 1983 7(6):507-519. [PubMed: 6625048]

2. Demetri GD, Benjamin RS, Blanke CD, et al. NCCN Task Force report: management of patients with gastrointestinal stromal tumor (GIST)--update of the NCCN clinical practice guidelines. J Natl Compr Canc Netw. Jul; 2007 5(Suppl 2):S1-29. quiz S30. [PubMed: 17624289]

3. Kindblom LG, Remotti HE, Aldenborg F, Meis-Kindblom JM. Gastrointestinal pacemaker cell tumor (GIPACT): gastrointestinal stromal tumors show phenotypic characteristics of the interstitial cells of Cajal. Am J Pathol. May; 1998 152(5):1259-1269. [PubMed: 9588894]

4. Rubin BP, Singer S, Tsao C, et al. KIT activation is a ubiquitous feature of gastrointestinal stromal tumors. Cancer Res. Nov 15; 2001 61(22):8118-8121. [PubMed: 11719439]

5. Heinrich MC, Corless CL, Duensing A, et al. PDGFRA activating mutations in gastrointestinal stromal tumors. Science. Jan 31; 2003 299(5607):708-710. [PubMed: 12522257]

6. Antonescu CR, Sommer G, Sarran L, et al. Association of KIT exon 9 mutations with nongastric primary site and aggressive behavior: KIT mutation analysis and clinical correlates of 120 gastrointestinal stromal tumors. Clin Cancer Res. Aug 15; 2003 9(9):3329-3337. [PubMed: 12960119]

7. Joensuu H, Roberts PJ, Sarlomo-Rikala M, et al. Effect of the tyrosine kinase inhibitor STI571 in a patient with a metastatic gastrointestinal stromal tumor. N Engl J Med. Apr 5; 2001 344(14):10521056. [PubMed: 11287975]

8. Blanke CD, Demetri GD, von Mehren M, et al. Long-term results from a randomized phase II trial of standard- versus higher-dose imatinib mesylate for patients with unresectable or metastatic gastrointestinal stromal tumors expressing KIT. J Clin Oncol. Feb 1; 2008 26(4):620-625. [PubMed: 18235121]

9. DeMatteo RP, Lewis JJ, Leung D, Mudan SS, Woodruff JM, Brennan MF. Two hundred gastrointestinal stromal tumors: recurrence patterns and prognostic factors for survival. Ann Surg. Jan; 2000 231(1):51-58. [PubMed: 10636102]

10. Nishida T, Hirota S, Taniguchi M, et al. Familial gastrointestinal stromal tumours with germline mutation of the KIT gene. Nat Genet. Aug; 1998 19(4):323-324. [PubMed: 9697690]

11. Chompret A, Kannengiesser C, Barrois M, et al. PDGFRA germline mutation in a family with multiple cases of gastrointestinal stromal tumor. Gastroenterology. Jan; 2004 126(1):318-321. [PubMed: 14699510]

12. Graadt van Roggen JF, van Velthuysen ML, Hogendoorn PC. The histopathological differential diagnosis of gastrointestinal stromal tumours. J Clin Pathol. Feb; 2001 54(2):96-102. [PubMed: 11215292]

13. Nilsson B, Bumming P, Meis-Kindblom JM, et al. Gastrointestinal stromal tumors: the incidence, prevalence, clinical course, and prognostication in the preimatinib mesylate era--a populationbased study in western Sweden. Cancer. Feb 15; 2005 103(4):821-829. [PubMed: 15648083]

14. Agaram NP, Laquaglia MP, Ustun B, et al. Molecular characterization of pediatric gastrointestinal stromal tumors. Clin Cancer Res. May 15; 2008 14(10):3204-3215. [PubMed: 18483389]

15. Sepe PS, Moparty B, Pitman MB, Saltzman JR, Brugge WR. EUS-guided FNA for the diagnosis of GI stromal cell tumors: sensitivity and cytologic yield. Gastrointest Endosc. Aug; 2009 70(2):254261. [PubMed: 19482280]

16. Katz SC, DeMatteo RP. Gastrointestinal stromal tumors and leiomyosarcomas. J Surg Oncol. Mar 15; 2008 97(4):350-359. [PubMed: 18286477]

17. Dematteo RP, Gold JS, Saran L, et al. Tumor mitotic rate, size, and location independently predict recurrence after resection of primary gastrointestinal stromal tumor (GIST). Cancer. Feb 1; 2008 112(3):608-615. [PubMed: 18076015]

18. Gold JS, Gonen M, Gutierrez A, et al. Development and validation of a prognostic nomogram for recurrence-free survival after complete surgical resection of localised primary gastrointestinal stromal tumour: a retrospective analysis. Lancet Oncol. Nov; 2009 10(11):1045-1052. [PubMed: 19793678] 
19. Miettinen M, Lasota J. Gastrointestinal stromal tumors: review on morphology, molecular pathology, prognosis, and differential diagnosis. Arch Pathol Lab Med. Oct; 2006 130(10):14661478. [PubMed: 17090188]

20. Fujimoto Y, Nakanishi Y, Yoshimura K, Shimoda T. Clinicopathologic study of primary malignant gastrointestinal stromal tumor of the stomach, with special reference to prognostic factors: analysis of results in 140 surgically resected patients. Gastric Cancer. 2003; 6(1):39-48. [PubMed: 12673425]

21. Novitsky YW, Kercher KW, Sing RF, Heniford BT. Long-term outcomes of laparoscopic resection of gastric gastrointestinal stromal tumors. Ann Surg. Jun; 2006 243(6):738-745. discussion 745737. [PubMed: 16772777]

22. Ng EH, Pollock RE, Munsell MF, Atkinson EN, Romsdahl MM. Prognostic factors influencing survival in gastrointestinal leiomyosarcomas. Implications for surgical management and staging. Ann Surg. Jan; 1992 215(1):68-77. [PubMed: 1731651]

23. Dematteo RP, Heinrich MC, El-Rifai WM, Demetri G. Clinical management of gastrointestinal stromal tumors: before and after STI-571. Hum Pathol. May; 2002 33(5):466-477. [PubMed: 12094371]

24. D'Amato G, Steinert DM, McAuliffe JC, Trent JC. Update on the biology and therapy of gastrointestinal stromal tumors. Cancer Control. Jan-Feb;2005 12(1):44-56. [PubMed: 15668652]

25. Maluccio MA, Covey AM, Schubert J, et al. Treatment of metastatic sarcoma to the liver with bland embolization. Cancer. Oct 1; 2006 107(7):1617-1623. [PubMed: 16955508]

26. Chaudhry UI, DeMatteo RP. Management of resectable gastrointestinal stromal tumor. Hematol Oncol Clin North Am. Feb; 2009 23(1):79-96. viii. [PubMed: 19248972]

27. Demetri GD, von Mehren M, Blanke CD, et al. Efficacy and safety of imatinib mesylate in advanced gastrointestinal stromal tumors. N Engl J Med. Aug 15; 2002 347(7):472-480. [PubMed: 12181401]

28. Verweij J, Casali PG, Zalcberg J, et al. Progression-free survival in gastrointestinal stromal tumours with high-dose imatinib: randomised trial. Lancet. Sep-Oct;2004 364(9440):1127-1134. [PubMed: 15451219]

29. Blanke CD, Rankin C, Demetri GD, et al. Phase III randomized, intergroup trial assessing imatinib mesylate at two dose levels in patients with unresectable or metastatic gastrointestinal stromal tumors expressing the kit receptor tyrosine kinase: S0033. J Clin Oncol. Feb 1; 2008 26(4):626632. [PubMed: 18235122]

30. DeMatteo, RP.; Owzar, K.; Antonescu, CR.; Maki, R. Efficacy of adjuvant imatinib mesylate following complete resection of localized, primary gastrointestinal stromal tumor (GIST) at high risk of recurrence: The U.S. Intergroup phase II trial ACOSOG Z9000. 2008 Gastrointestinal Cancers Symposium; January 25-27, 2008; Orlando, FL.

31. Dematteo RP, Ballman KV, Antonescu CR, et al. Adjuvant imatinib mesylate after resection of localised, primary gastrointestinal stromal tumour: a randomised, double-blind, placebo-controlled trial. Lancet. Mar 28; 2009 373(9669):1097-1104. [PubMed: 19303137]

32. Eisenberg BL, Harris J, Blanke CD, et al. Phase II trial of neoadjuvant/adjuvant imatinib mesylate (IM) for advanced primary and metastatic/recurrent operable gastrointestinal stromal tumor (GIST): early results of RTOG 0132/ACRIN 6665. J Surg Oncol. Jan 1; 2009 99(1):42-47. [PubMed: 18942073]

33. DeMatteo RP, Shah A, Fong Y, Jarnagin WR, Blumgart LH, Brennan MF. Results of hepatic resection for sarcoma metastatic to liver. Ann Surg. Oct; 2001 234(4):540-547. discussion 547548. [PubMed: 11573047]

34. van Oosterom AT, Judson I, Verweij J, et al. Safety and efficacy of imatinib (STI571) in metastatic gastrointestinal stromal tumours: a phase I study. Lancet. Oct 27; 2001 358(9291):1421-1423. [PubMed: 11705489]

35. DeMatteo RP, Maki RG, Singer S, Gonen M, Brennan MF, Antonescu CR. Results of tyrosine kinase inhibitor therapy followed by surgical resection for metastatic gastrointestinal stromal tumor. Ann Surg. Mar; 2007 245(3):347-352. [PubMed: 17435539] 
36. Gronchi A, Fiore M, Miselli F, et al. Surgery of residual disease following molecular-targeted therapy with imatinib mesylate in advanced/metastatic GIST. Ann Surg. Mar; 2007 245(3):341346. [PubMed: 17435538]

37. Raut CP, Posner M, Desai J, et al. Surgical management of advanced gastrointestinal stromal tumors after treatment with targeted systemic therapy using kinase inhibitors. J Clin Oncol. May 20; 2006 24(15):2325-2331. [PubMed: 16710031]

38. van der Zwan SM, DeMatteo RP. Gastrointestinal stromal tumor: 5 years later. Cancer. Nov 1; 2005 104(9):1781-1788. [PubMed: 16136600]

39. Blay JY, Le Cesne A, Ray-Coquard I, et al. Prospective multicentric randomized phase III study of imatinib in patients with advanced gastrointestinal stromal tumors comparing interruption versus continuation of treatment beyond 1 year: the French Sarcoma Group. J Clin Oncol. Mar 20; 2007 25(9):1107-1113. [PubMed: 17369574]

40. Van Glabbeke M, Verweij J, Casali PG, et al. Initial and late resistance to imatinib in advanced gastrointestinal stromal tumors are predicted by different prognostic factors: a European Organisation for Research and Treatment of Cancer-Italian Sarcoma Group-Australasian Gastrointestinal Trials Group study. J Clin Oncol. Aug 20; 2005 23(24):5795-5804. [PubMed: 16110036]

41. Joensuu H. Gastrointestinal stromal tumor (GIST). Ann Oncol. Sep; 2006 17( Suppl 10):x280-286. [PubMed: 17018739]

42. Heinrich MC, Corless CL, Demetri GD, et al. Kinase mutations and imatinib response in patients with metastatic gastrointestinal stromal tumor. J Clin Oncol. Dec 1; 2003 21(23):4342-4349. [PubMed: 14645423]

43. Antonescu CR, Besmer P, Guo T, et al. Acquired resistance to imatinib in gastrointestinal stromal tumor occurs through secondary gene mutation. Clin Cancer Res. Jun 1; 2005 11(11):4182-4190. [PubMed: 15930355]

44. Debiec-Rychter M, Cools J, Dumez H, et al. Mechanisms of resistance to imatinib mesylate in gastrointestinal stromal tumors and activity of the PKC412 inhibitor against imatinib-resistant mutants. Gastroenterology. Feb; 2005 128(2):270-279. [PubMed: 15685537]

45. Prenen H, Cools J, Mentens N, et al. Efficacy of the kinase inhibitor SU11248 against gastrointestinal stromal tumor mutants refractory to imatinib mesylate. Clin Cancer Res. Apr 15; 2006 12(8):2622-2627. [PubMed: 16638875]

46. Demetri GD, van Oosterom AT, Garrett CR, et al. Efficacy and safety of sunitinib in patients with advanced gastrointestinal stromal tumour after failure of imatinib: a randomised controlled trial. Lancet. Oct 14; 2006 368(9544):1329-1338. [PubMed: 17046465]

47. Raut CP, Wang Q, Manola J, et al. Cytoreductive Surgery in Patients with Metastatic Gastrointestinal Stromal Tumor Treated with Sunitinib Malate. Ann Surg Oncol. Nov 7.2009 


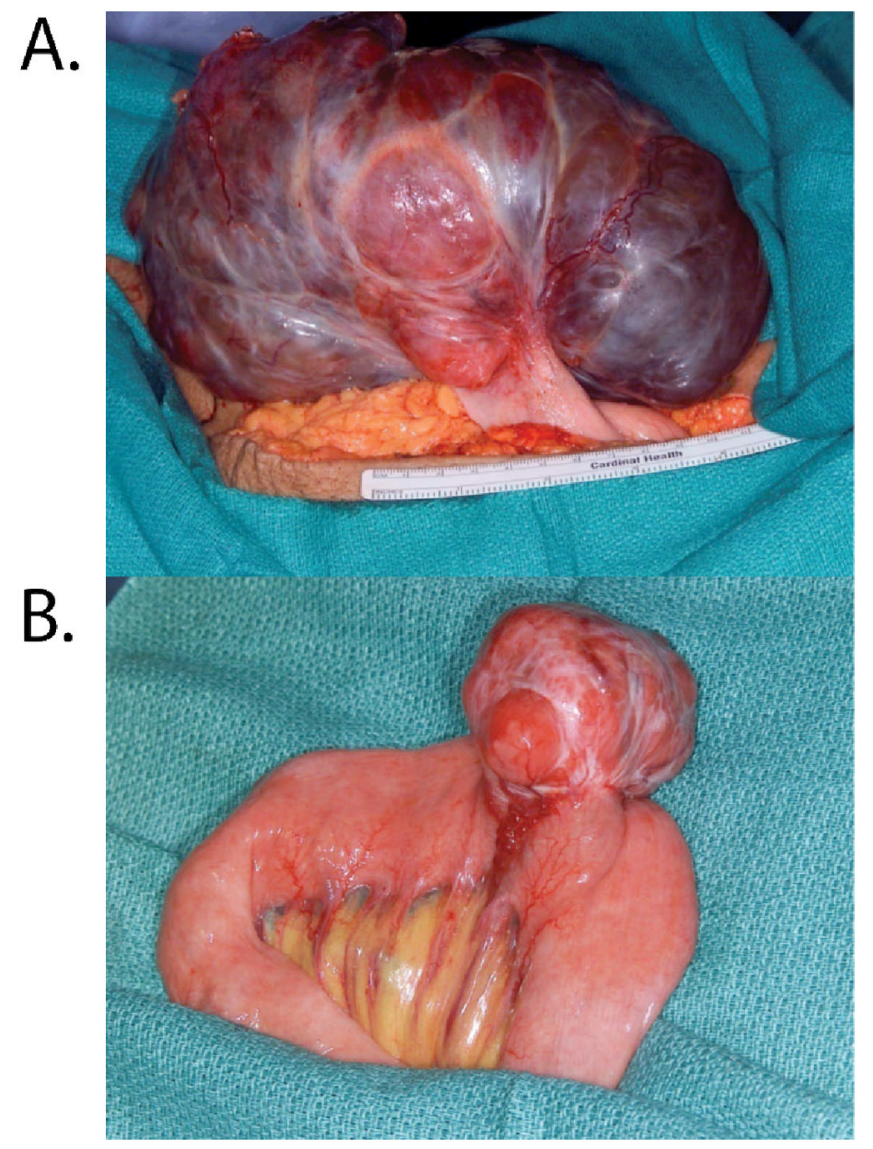

FIGURE 1.

(A) A large exophytic gastric GIST. (B) GIST emanating from the anti- mesenteric border of jejunum. 
A. B.

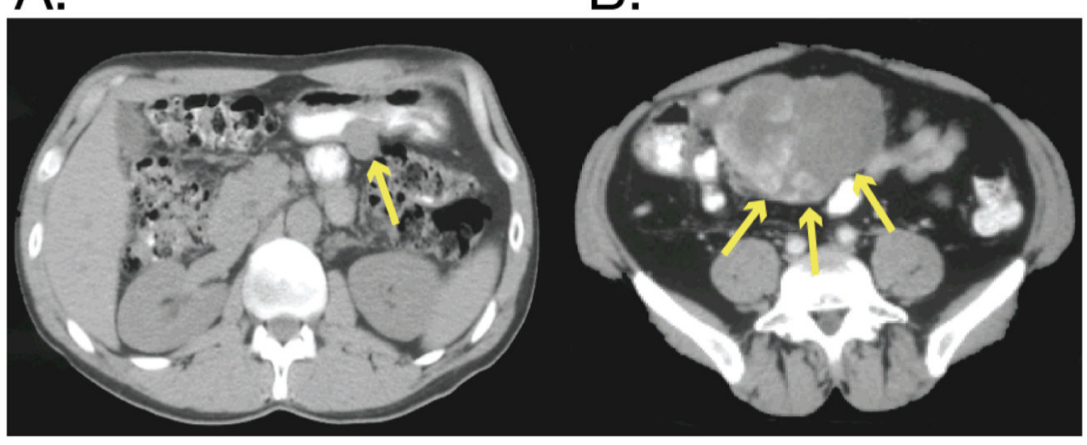

FIGURE 2.

(A) CT scan showing a small gastric GIST arising from the posterior wall of the stomach (arrowhead). (B) A large GIST arising from the mesocolon of the right colon (arrowheads). 


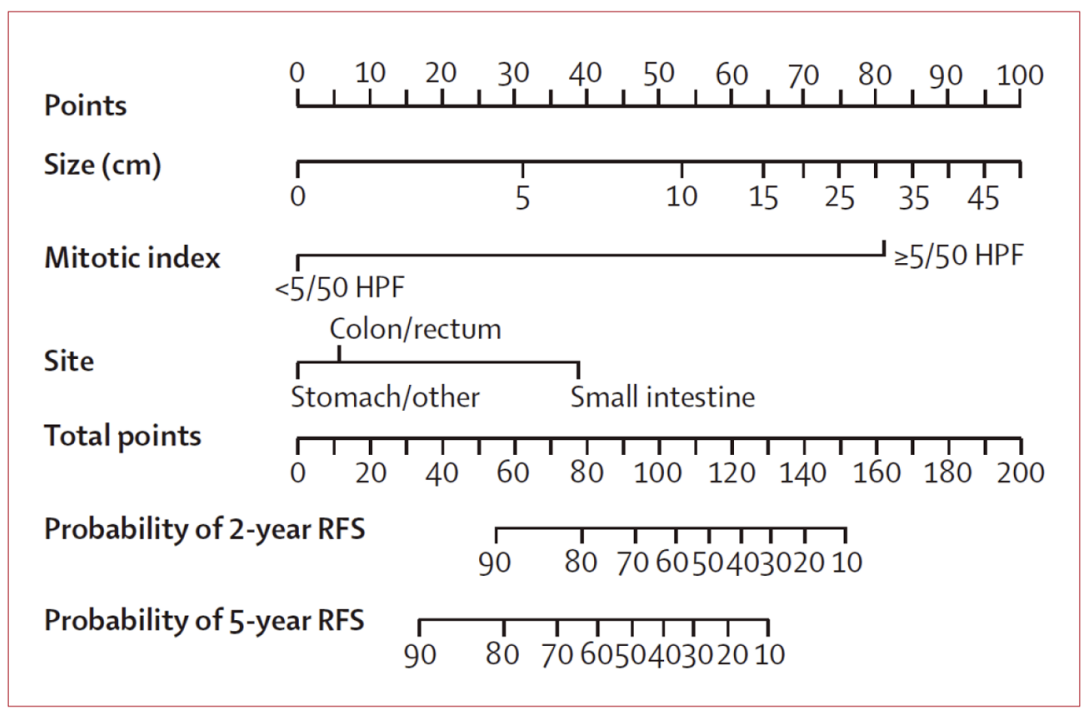

FIGURE 3.

Nomogram to estimate 2 and 5 year recurrence-free survival after surgical resection of primary GIST in the absence of tyrosine kinase inhibitor therapy. (From Gold JS et al. Development and validation of a prognostic nomogram for recurrence-free survival after complete surgical resection of localised primary gastrointestinal stromal tumour: a retrospective analysis. Lancet Oncol 2009; 10:1045; with permission.) 


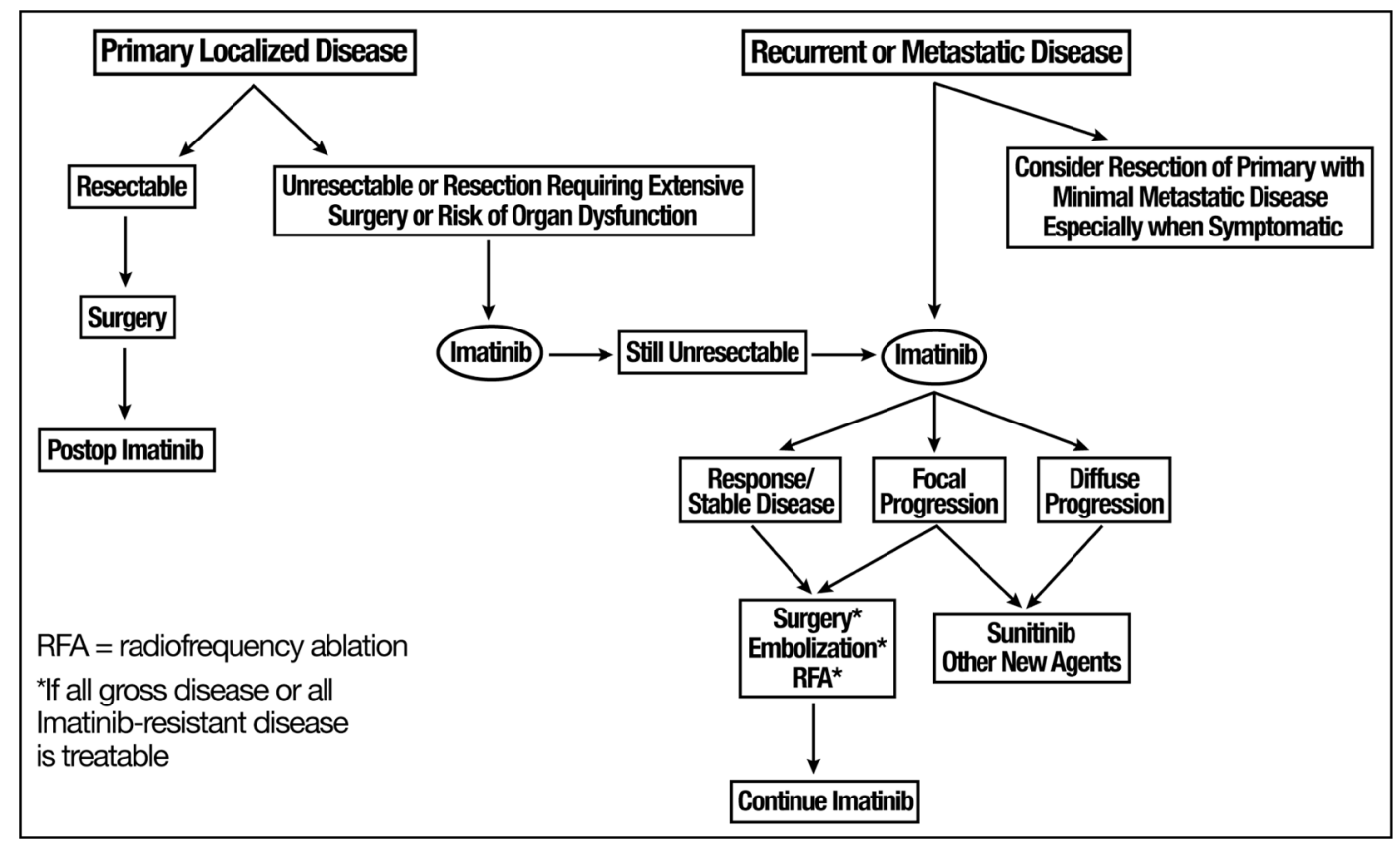

FIGURE 4.

Algorithm for the treatment of GIST. (From Gold JS, DeMatteo RP. Combined Surgical and Molecular Therapy- The Gastrointestinal Stromal Tumor Model. Ann Surg 2006; 244(2): 176-184; with permission.) 